\title{
Control of Main-Chain Stereostructure of Graft Polymers* via Stereospecific Anionic Copolymerization of Syndiotactic Poly(methyl methacrylate) Macromonomer Having Methacryloyl Function with Methacrylate Monomers
}

\author{
Tatsuki Kitayama, Osamu Nakagawa, Shigeki Kishiro, \\ Takafumi NishiUra, and Koichi HatadA \\ Department of Chemistry, Faculty of Engineering Science, Osaka University, \\ Toyonaka, Osaka 560, Japan
}

(Received December 17, 1992)

\begin{abstract}
Highly syndiotactic PMMA macromonomer having methacryloyl group as a polymerizable function was prepared from the corresponding living PMMA anion formed with $t-\mathrm{C}_{4} \mathrm{H}_{9} \mathrm{Li} /\left(n-\mathrm{C}_{4} \mathrm{H}_{9}\right)_{3} \mathrm{Al}(1 / 3)$ in toluene at $-78^{\circ} \mathrm{C}$. Anionic copolymerization of the macromonomer with methyl (MMA) or ethyl methacrylate was carried out with anionic initiators. Copolymerization with 1,1-diphenylhexyllithium in tetrahydrofuran at $-78^{\circ} \mathrm{C}$ gave graft polymers* with syndiotactic main chain in high yields. Copolymerization with $t-\mathrm{C}_{4} \mathrm{H}_{9} \mathrm{MgBr}$ in toluene at $-78^{\circ} \mathrm{C}$ afforded graft polymers with highly isotactic main chain in good yields, although the molecular weight distributions were broad. The graft polymer with main-chain MMA units obtained in the latter system exhibited melting endotherm due to stereocomplex formation between isotactic main chain and syndiotactic side chains.
\end{abstract}

KEY WORDS Macromonomer / Graft Polymer / Stereoregularity / Anionic

Copolymerization / Methacrylate / Poly(methyl methacrylate) / NMR / End

Group /

Many investigations have been reported on the preparation and polymerization of macromonomer aiming at the structural control of graft polymer and comb-like polymer. ${ }^{1-11}$ It has been well recognized that stereoregularity of polymer is one of the most important characteristics which affect polymer properties. However, little attention has been paid on the stereoregularity of the macromonomer itself and the polymer or copolymer obtained therefrom. We have reported the preparation of isotactic (it-) and syndiotactic (st-) poly(methyl methacrylate) (PMMA) macromonomers with styrene-type end group, which give graft polymers and comb-like polymers with stereoregular PMMA branches. ${ }^{6-10}$ Recently, we have also reported the stereospecific anionic polymerization of polyisobutylene macromonomer having methacryloyl function, which afforded comb-like polymers with stereoregular main chain. ${ }^{11}$ In this case the methacryloyl group was selected as a polymerizable function,

* In the IUPAC's definitions [Basic Definitions of Terms Relating to Polymer (1974), Pure Appl. Chem., 40, 477 (1974)], graft polymer and graft copolymer are defined in the different categories, structure-based and source-based, respectively. In the structure-based definition, graft polymer is defined as a polymer whose molecules have one or more species of block connected to the main chain as side chains, these side chains having constitutional or configurational features different from the constitutional units comprising the main chain, exclusive of junction points. The polymers dealt in this article are mostly graft polymers in this definition except for the polymer comprised of $s t$-PMMA main chain and st-PMMA side chains, which should be called branched polymer. For avoiding the confusion, "graft polymer" is used in this paper to describe the products from copolymerization of macromonomer and RMA. 
because many papers have been published on the stereospecific polymerization of methacrylates with various anionic initiators and a wide variety of stereoregular polymethacrylates can be obtained by selecting proper initiator and polymerization conditions. ${ }^{12,13}$

The next research objective in this line will be the synthesis of graft polymer or comb-like polymer comprising stereoregular branches with high stereoregularity of the main chain. For the first step toward the objective, we attempted the synthesis of st-PMMA macromonomer having methacryloyl function and its copolymerization with low molecular weight methacrylate by anionic initiators to obtain the stereoregular graft polymers with controlled stereoregularities of the main chain as well as side chains.

\section{EXPERIMENTAL}

\section{Materials}

Toluene, purified in the usual manner, was mixed with a small amount of $n-\mathrm{C}_{4} \mathrm{H}_{9} \mathrm{Li}$ and distilled under vacuum. Tetrahydrofuran (THF), purified by distillation from calcium dihydride $\left(\mathrm{CaH}_{2}\right)$, was distilled again over lithium aluminium hydride and vacuum-distilled just before use. Methyl (MMA) and ethyl (EMA) methacrylates, allyl iodide, and $N, N$, $N^{\prime}, N^{\prime}$-tetramethylethylenediamine (TMEDA) were purified by distillation and then distilled over $\mathrm{CaH}_{2}$ under vacuum just before use. 9-Borabicyclo[3.3.1] nonane (9-BBN) was purchased as a THF solution and used as received. Pyridine was purified by distillation and dried over molecular sieves 4A (MS-4A). Methacryloyl chloride was synthesized from methacrylic acid and phosphorus trichloride. The methacryloyl chloride, purified by distillation, was dried over MS-4A at $0^{\circ} \mathrm{C}$ for $2 \mathrm{~h}$ and vacuum-distilled. $t-\mathrm{C}_{4} \mathrm{H}_{9} \mathrm{Li}$ and $\left(n-\mathrm{C}_{4} \mathrm{H}_{9}\right)_{3} \mathrm{Al}$ were obtained commercially and used as heptane solutions. $t-\mathrm{C}_{4} \mathrm{H}_{9} \mathrm{MgBr}$ was prepared from $t-\mathrm{C}_{4} \mathrm{H}_{9} \mathrm{Br}$ and $\mathrm{Mg}$ in diethyl ether. ${ }^{14}$ Diphenylhexyllithium (DPHLi) was synthe- sized from 1,1-diphenylethylene and $n-\mathrm{C}_{4} \mathrm{H}_{9} \mathrm{Li}$ in THF. ${ }^{15-17}$

\section{Preparation of st-PMMA Macromonomer}

The st-PMMA macromonomer having methacryloyl function was prepared by three-step reactions from st-PMMA anion as shown Scheme 1.

(1) Preparation of st-PMMA with Allyl End Group (st-PMMA-CH $-\mathrm{CH}=\mathrm{CH}_{2}$ ) stPMMA anion was obtained by the polymerization of MMA initiated with $t-\mathrm{C}_{4} \mathrm{H}_{9} \mathrm{Li} /(n$ $\left.\mathrm{C}_{4} \mathrm{H}_{9}\right)_{3} \mathrm{Al}(1 / 3)^{18}$ at $-78^{\circ} \mathrm{C}$ in toluene. The polymerization was carried out in a glass ampoule filled with dry nitrogen. $t-\mathrm{C}_{4} \mathrm{H}_{9} \mathrm{Li}$ was added to a solution of $\left(n-\mathrm{C}_{4} \mathrm{H}_{9}\right)_{3} \mathrm{Al}$ in toluene cooled to $-78^{\circ} \mathrm{C}$. MMA was added slowly to the initiator mixture to initiate the polymerization reaction. After the completion of the polymerization, 10 equivalents of allyl iodide to the living anions were added to the polymerization mixture at $-78^{\circ} \mathrm{C}$ with vigorous stirring. After $1 \mathrm{~h}$ TMEDA in toluene was added to this mixture and the reaction was continued at $-78^{\circ} \mathrm{C}$ for $24 \mathrm{~h}$ and then at $0^{\circ} \mathrm{C}$ for further $3 \mathrm{~h}$. The reaction mixture was centrifuged to remove insoluble materials and the supernatant was poured into a large amount of hexane. The precipitated polymer was collected by filtration, washed successively with hexane, diluted aqueous $\mathrm{HCl}$, water and hexane, and dried under vacuum at

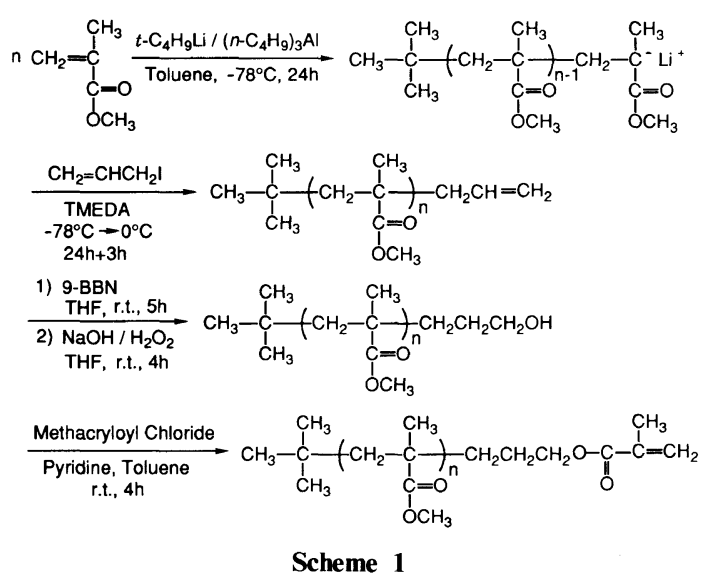

Scheme 1 
$40^{\circ} \mathrm{C}$. The polymer obtained was redissolved in benzene and recovered from the benzene solution by freeze-drying after removing undissolved materials by centrifugation.

(2) Preparation of st-PMMA with Hydroxyl End Group (st-PMMA-(CH$\left.)_{3}-\mathrm{OH}\right)$ To a THF solution of $s t$-PMMA- $\mathrm{CH}_{2}-\mathrm{CH}=\mathrm{CH}_{2}$, 9-BBN in THF $(0.5 \mathrm{M})$ was added at room temperature under dry nitrogen. After $5 \mathrm{~h}$ aqueous $\mathrm{NaOH}(3 \mathrm{~N})$ and aqueous $\mathrm{H}_{2} \mathrm{O}_{2}$ $(30 \%)$ were added successively. Aqueous $\mathrm{H}_{2} \mathrm{O}_{2}$ was added carefully to the solution so that the temperature of the reaction mixture was kept below $30^{\circ} \mathrm{C}$ in order to prevent decomposition of $\mathrm{H}_{2} \mathrm{O}_{2}$. The mixture was stirred for $4 \mathrm{~h}$ at room temperature. After the completion of the reaction, toluene and $\mathrm{K}_{2} \mathrm{CO}_{3}$ were added to the mixture and the organic layer was separated and concentrated under reduced pressure. The remaining solution was poured into a large amount of hexane and the precipitated polymer was collected by filtration, washed successively with hexane, diluted aqueous $\mathrm{HCl}$, water, and hexane, and dried in vacuo at $40^{\circ} \mathrm{C}$.

(3) Preparation of st-PMMA Macromonomer with Methacryloyl End Group st-PMMA$\left(\mathrm{CH}_{2}\right)_{3}-\mathrm{OH}$ was dissolved in toluene under dry nitrogen. Methacryloyl chloride was added to the solution in the presence of pyridine at $0^{\circ} \mathrm{C}$, and the reaction mixture was stirred for $4 \mathrm{~h}$ at room temperature. Then, the mixture was poured into a large amount of hexane. The precipitated polymer was collected by filtration, washed successively with hexane, diluted aqueous $\mathrm{HCl}$ solution, water and hexane, and dried under vacuum at room temperature.

\section{Preparation of Graft Polymer}

The copolymerizations of the macromonomer with MMA or EMA were carried out under dry nitrogen in glass ampoules. The macromonomer was dissolved in benzene and the solution was dried over $\mathrm{CaH}_{2}$. The $\mathrm{CaH}_{2}$ was removed by filtration using membrane filter made of Teflon under dry nitrogen, and the macromonomer was recovered by freezedrying. The macromonomer was redissolved in the polymerization solvent, and MMA or EMA was added to the solution. The polymerization was initiated by adding an initiator to the mixture at $-78^{\circ} \mathrm{C}$. After a certain polymerization time the reaction was quenched by adding a small amount of methanol containing acetic acid. The reaction mixture obtained with $t-\mathrm{C}_{4} \mathrm{H}_{9} \mathrm{MgBr}$ in toluene was dissolved in benzene after removing the polymerization solvent under vacuum. The mixture was recovered from the benzene solution by freeze-drying after removing a small amount of insoluble materials by centrifugation. The mixture obtained with DPHLi in THF was poured into a large amount of hexane. The precipitated polymer was collected by filtration, washed and dried under vacuum at $40^{\circ} \mathrm{C}$.

To separate the graft polymer from the unreacted $s t$-PMMA macromonomer the mixtures were redissolved in toluene or chloroform and certain amounts of hexane were added slowly to the solutions. The graft polymers precipitated were isolated from the remaining st-PMMA macromonomer by repeated reprecipitation.

\section{Measurements}

${ }^{1} \mathrm{H}$ NMR spectra of the polymers were recorded on a JNM GSX270 NMR spectrometer (JEOL) at $270 \mathrm{MHz}$ or a JNM GX500 NMR spectrometer (JEOL) at $500 \mathrm{MHz} .{ }^{13} \mathrm{C}$ NMR spectra of the polymers were measured on the JNM GSX270 NMR spectrometer at $67.8 \mathrm{MHz}$.

Gel permeation chromatography (GPC) was performed on a JASCO TRI ROTAR-V chromatograph equipped with Shodex GPC columns KF-80M $(30 \mathrm{~cm} \times 0.80 \mathrm{~cm})$ and $\mathrm{KF}$ $802.5(30 \mathrm{~cm} \times 0.80 \mathrm{~cm})$ with maximum porosities of $2 \times 10^{7}$ and $2 \times 10^{4}$, respectively, using THF as an eluent or on a JASCO TRI ROTAR-II ${ }^{\mathrm{P}}$ chromatograph equipped with Shodex GPC columns K-806L $(30 \mathrm{~cm} \times$ 
Table I. Preparation of $s t$-PMMA with allyl end group ${ }^{\mathrm{a}}$

\begin{tabular}{|c|c|c|c|c|c|c|c|c|c|c|c|}
\hline \multirow{2}{*}{$\begin{array}{c}\text { MMA } \\
\text { mmol }\end{array}$} & \multirow{2}{*}{$\frac{\text { Init. }^{b}}{\mathrm{mmol}}$} & \multirow{2}{*}{$\begin{array}{c}\text { Iodide }^{\mathrm{c}} \\
\mathrm{mmol}\end{array}$} & \multirow{2}{*}{$\frac{\text { TMEDA }^{\mathrm{d}}}{\mathrm{mmol}}$} & \multirow{2}{*}{$\frac{\text { Yield }}{\%}$} & \multicolumn{2}{|c|}{$\bar{M}_{n}$} & \multirow{2}{*}{$\bar{M}_{w} / \bar{M}_{n}^{\mathrm{f}}$} & \multicolumn{3}{|c|}{ Tacticity $^{\mathrm{e}}$} & \multirow{2}{*}{$\frac{f^{\mathrm{g}}}{\%}$} \\
\hline & & & & & $\mathrm{NMR}^{\mathrm{e}}$ & Calcd & & $m m$ & $m r$ & $r r$ & \\
\hline 192 & 8.0 & 75.7 & 41.2 & 95 & 3310 & 2380 & 1.07 & 1 & 10 & 89 & 99 \\
\hline
\end{tabular}

a Solvent, toluene $200 \mathrm{ml}$; temperature, $-78^{\circ} \mathrm{C}$; time, $24 \mathrm{~h}$.

b Initiator: $t-\mathrm{C}_{4} \mathrm{H}_{9} \mathrm{Li} /\left(n-\mathrm{C}_{4} \mathrm{H}_{9}\right)_{3} \mathrm{Al}=1 / 3, t-\mathrm{C}_{4} \mathrm{H}_{9} \mathrm{Li} 8.0 \mathrm{mmol}$.

c Allyl iodide.

d $N, N, N^{\prime}, N^{\prime}$-Tetramethylethylenediamine was added as a toluene solution $\left(4.02 \mathrm{mmol} \mathrm{g}^{-1}\right)$.

e Determined by ${ }^{1} \mathrm{H}$ NMR spectroscopy.

${ }^{f}$ Determined by GPC.

${ }^{\mathrm{g}}$ Functionality of allyl group determined by ${ }^{1} \mathrm{H}$ NMR spectroscopy.

$0.80 \mathrm{~cm}) \times 2$ with maximum porosity of $2 \times 10^{7}$ using chloroform as an eluent. The chromatograms were calibrated against standard polystyrene samples. Molecular weight of graft polymers determined based on the calibration with the linear polymer standards were used without taking the branching factor into account as the first approximation.

Differential scanning calorimetric (DSC) analysis was performed on a Rigaku DSC 8230 calorimeter at a heating rate of $10^{\circ} \mathrm{C} \mathrm{min}^{-1}$.

\section{RESULTS AND DISCUSSION}

\section{Preparation of st-PMMA Macromonomer}

st-PMMA macromonomer was prepared from $s t$-PMMA living anion formed with $t$ $\mathrm{C}_{4} \mathrm{H}_{9} \mathrm{Li} /\left(n-\mathrm{C}_{4} \mathrm{H}_{9}\right)_{3} \mathrm{Al}^{18}$ by three step reactions. The results of each reaction are summarized in Tables I-III.

(1) Preparation of st-PMMA-CH$-\mathrm{CH}=$ $\mathrm{CH}_{2}$ PMMA having allyl end group has been prepared by the reaction of allyl bromide and PMMA living anion formed in THF with DPHLi. ${ }^{15}$ Tacticity of the PMMA was predominantly syndiotactic but not so high. To obtain highly syndiotactic PMMA macromonomer, we utilized the living polymerization of MMA with $t-\mathrm{C}_{4} \mathrm{H}_{9} \mathrm{Li} /\left(n-\mathrm{C}_{4} \mathrm{H}_{9}\right)_{3} \mathrm{Al}(1 / 3),{ }^{18}$ which has been successfully applied to the preparation of styrene-type, highly syndiotactic PMMA macromonomer. ${ }^{8}$ Since the living st-PMMA anion is less reactive than that
Table II. Preparation of $s t$-PMMA with hydroxyl end group

\begin{tabular}{|c|c|}
\hline THF & $160 \mathrm{ml}$ \\
\hline$s t$-PMMA- $\mathrm{CH}_{2}-\mathrm{CH}=\mathrm{CH}_{2}$ & $16.6 \mathrm{~g}$ \\
\hline Allyl end group & $5.0 \mathrm{mmol}$ \\
\hline $9-\mathrm{BBN}^{\mathrm{a}}$ & $53 \mathrm{mmol}$ \\
\hline $\mathrm{NaOH}^{\mathrm{b}}$ & $53 \mathrm{mmol}$ \\
\hline $\mathrm{H}_{2} \mathrm{O}_{2}^{\mathrm{c}}$ & $160 \mathrm{mmol}$ \\
\hline Yield & $100 \%$ \\
\hline Functionality of $-\mathrm{OH}^{\mathrm{d}}$ & $96 \%$ \\
\hline \multicolumn{2}{|c|}{$\begin{array}{l}\text { a } 0.5 \mathrm{M} \text { THF solution of 9-borabicyclo[3.3.1]nonane. } \\
\text { b } 3 \mathrm{~N} \text { aqueous solution. } \\
\text { c } 30 \% \text { aqueous solution. } \\
\text { d Determined by }{ }^{1} \mathrm{H} \text { NMR spectroscopy. }\end{array}$} \\
\hline \multicolumn{2}{|c|}{ Table III. Preparation of $s t$-PMMA macromonomer } \\
\hline Toluene & $20 \mathrm{ml}$ \\
\hline$s t$-PMMA- $\left(\mathrm{CH}_{2}\right)_{3}-\mathrm{OH}$ & $2.00 \mathrm{~g}$ \\
\hline Hydroxyl end group & $0.58 \mathrm{mmol}$ \\
\hline Pyridine & $6.2 \mathrm{mmol}$ \\
\hline Methacryloyl chloride & $1.9 \mathrm{mmol}$ \\
\hline Yield & $95 \%$ \\
\hline $\begin{array}{l}\text { Functionality of } \\
\text { methacryloyl end group }\end{array}$ & $89 \%$ \\
\hline
\end{tabular}

a Determined by ${ }^{1} \mathrm{H}$ NMR spectroscopy.

formed in THF with DPHLi, allyl iodide instead of allyl bromide was used as a source of the allyl end group. From the experience in the synthesis of the styrene-type PMMA macromonomer, TMEDA was also used to facilitate the coupling reaction between the living PMMA and allyl iodide. The details of 

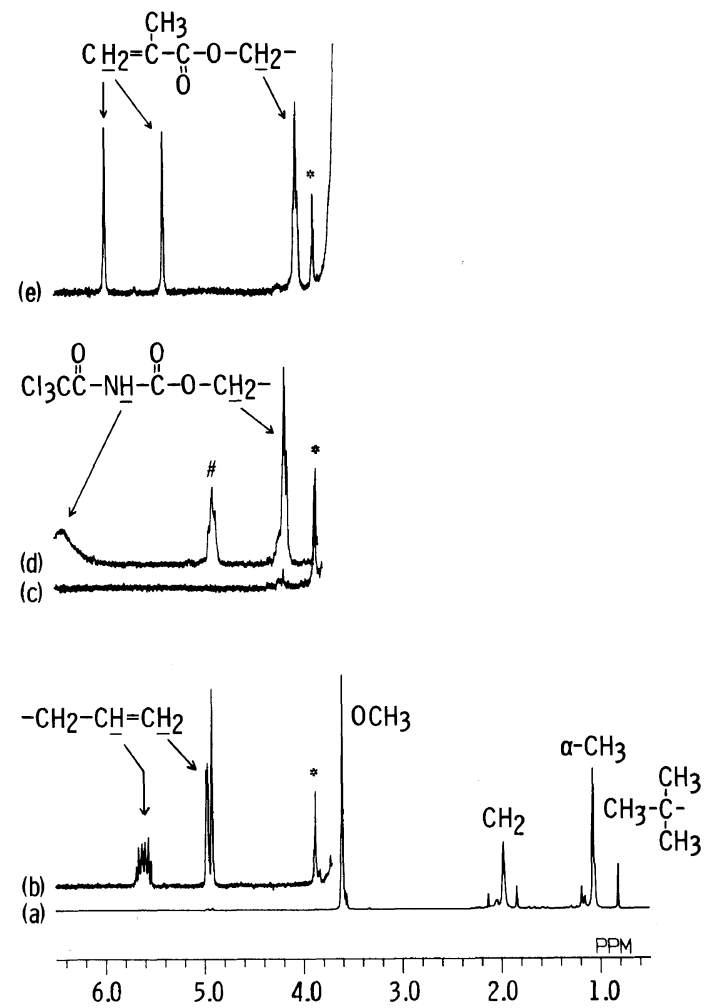

Figure 1. $270 \mathrm{MHz}{ }^{1} \mathrm{H}$ NMR spectra of $s t$-PMMA$\mathrm{CH}_{2}-\mathrm{CH}=\mathrm{CH}_{2}$ (a and b), st-PMMA- $\left(\mathrm{CH}_{2}\right)_{3}-\mathrm{OH}$ (c), stPMMA- $\left(\mathrm{CH}_{2}\right)_{3}-\mathrm{O}-\mathrm{CONH}-\mathrm{CO}-\mathrm{CCl}_{3}(\mathrm{~d})$, and $s t$-PMMA macromonomer (e) measured in nitrobenzene- $d_{5}$ at $110^{\circ} \mathrm{C}$. * ${ }^{13} \mathrm{C}$ satellite signal of $\mathrm{OCH}_{3}$ signal.

* Signal due to the reaction product of trichloroacetyl isocyanate and 1,5-cyclooctanediol derived from 9-BBN.

the coupling reaction are described in the Experimental section. The results and the ${ }^{1} \mathrm{H}$ NMR spectra of st-PMMA- $\mathrm{CH}_{2}-\mathrm{CH}=\mathrm{CH}_{2}$ are shown in Table $\mathrm{I}$ and Figures $1 \mathrm{a}$ and $1 \mathrm{~b}$, respectively. Number average molecular weight $\left(\bar{M}_{n}\right)$ was determined from the intensity ratio of the signals due to the protons of $t-\mathrm{C}_{4} \mathrm{H}_{9} \quad(0.82 \mathrm{ppm})$ and $\mathrm{OCH}_{3} \quad(3.61 \mathrm{ppm})$ (Figure 1a). The functionality of allyl end group was determined to be very close to unity from the intensity ratio of the signals due to $t-\mathrm{C}_{4} \mathrm{H}_{9}$ and olefinic protons in $-\mathrm{CH}_{2}-$ $\mathrm{C} \underline{\mathrm{H}}=\mathrm{C}_{2}$ group $\quad(-\mathrm{CH}=: 5.54-5.67 \mathrm{ppm}$, $=\mathrm{CH}_{2}: 4.92-4.98 \mathrm{ppm}$ ) (Figure $\left.1 \mathrm{~b}\right)$.

(2) Preparation of st-PMMA-( $\left.\mathrm{CH}_{2}\right)_{3}-\mathrm{OH}$
st-PMMA- $\left(\mathrm{CH}_{2}\right)_{3}-\mathrm{OH}$ was prepared from st-PMMA- $\mathrm{CH}_{2}-\mathrm{CH}=\mathrm{CH}_{2}$ through hydroboration with $9-\mathrm{BBN}$, and the results are summarized in Table II. Though the olefinic proton signals of $-\mathrm{CH}_{2}-\mathrm{CH}=\mathrm{C}_{2}$ disappeared completely in the ${ }^{1} \mathrm{H}$ NMR spectrum of the product as shown in Figure 1c, the functionality of hydroxyl end group could not be estimated from the spectrum. In order to determine the hydroxyl functionality, an excess amount of trichloroacetyl isocyanate was added to a nitrobenzene- $d_{5}$ solution of st-PMMA- $\left(\mathrm{CH}_{2}\right)_{3}-\mathrm{OH}$ in an NMR sample tube, which reacted with the hydroxyl group to form st-PMMA- $\left(\mathrm{CH}_{2}\right)_{3}-\mathrm{O}-\mathrm{CONH}-\mathrm{CO}-$ $\mathrm{CCl}_{3}$ immediately. The same method has been successfully utilized in the analysis of hydroxyl end groups of poly(ethylene oxide) ${ }^{19}$ and poly(propylene oxide) ${ }^{20}$. In the ${ }^{1} \mathrm{H}$ NMR spectrum of $s t$-PMMA- $\left(\mathrm{CH}_{2}\right)_{3}-\mathrm{O}-\mathrm{CONH}-\mathrm{CO}-\mathrm{CCl}_{3}$ shown in Figure 1d, a new signal ascribable to the methylene protons of $-\mathrm{CH}_{2}-\mathrm{O}-\mathrm{CONH}-$ $\mathrm{CO}-\mathrm{CCl}_{3}$ was observed at $4.17 \mathrm{ppm}$. Another new signal appeared at $4.91 \mathrm{ppm}$ was assigned to the reaction product of trichloroacetyl isocyanate and 1,5-cyclooctanediol derived from 9-BBN. The functionality of hydroxyl end group was determined to be 0.96 from the intensity ratio of the signals due to protons of $t-\mathrm{C}_{4} \mathrm{H}_{9}$ and $-\mathrm{CH}_{2}-\mathrm{O}-\mathrm{CONH}-\mathrm{CO}-\mathrm{CCl}_{3}$ (Figure 1d).

(3) Preparation of st-PMMA Macromonomer st-PMMA macromonomer was prepared from st-PMMA- $\left(\mathrm{CH}_{2}\right)_{3}-\mathrm{OH}$ and the results are shown in Table III. In the ${ }^{1} \mathrm{H}$ NMR spectrum of st-PMMA macromonomer, new signals ascribable to vinylidene protons of methacryloyl end group were observed at $5.40 \mathrm{ppm}$ and $5.99 \mathrm{ppm}$ (Figure 1e). The functionality of methacryloyl end group of the macromonomer was determined as 0.89 from the intensity ratio of the signals due to protons of $t-\mathrm{C}_{4} \mathrm{H}_{9}$ and the vinylidene group.

${ }^{13} \mathrm{C}$ NMR spectrum of the macromonomer showed the signals of the methacryloyl group as follows: $\mathrm{CH}_{2}=125.35,=\mathrm{C} 136.40, \mathrm{C}=\mathrm{O}$ 
Table IV. Copolymerization of $s t$-PMMA macromonomer (Mac) and methacrylate monomer (RMA) with DPHLi in THF at $-78^{\circ} \mathrm{C}^{\mathrm{a}}$

\begin{tabular}{|c|c|c|c|c|c|c|c|c|}
\hline \multirow{2}{*}{$\frac{\mathrm{Mac}^{\mathrm{b}}}{\mathrm{mmol}}$} & \multirow{2}{*}{$\frac{\text { Comonomer }}{\text { RMA (mmol) }}$} & \multirow{2}{*}{$\frac{\mathrm{RMA}}{\mathrm{Mac}^{\mathrm{b}}}$} & \multirow{2}{*}{$\frac{\text { Init. }^{c}}{\mathrm{mmol}}$} & \multirow{2}{*}{$\frac{\text { Time }}{\text { day }}$} & \multicolumn{2}{|c|}{ Conversion $^{\mathrm{d}}$} & \multicolumn{2}{|r|}{ Yield $^{\mathrm{e}} / \%$} \\
\hline & & & & & $\mathrm{Mac}^{\mathrm{b}}$ & RMA & Total & Graft polymer \\
\hline 0.13 & MMA (1.60) & 12.3 & 0.060 & 15.9 & 100 & - & 100 & 92 \\
\hline 0.13 & EMA $(0.61)$ & 5.1 & 0.058 & 11.8 & 100 & 100 & 100 & 71 \\
\hline 0.13 & EMA $(1.40)$ & 10.8 & 0.058 & 15.9 & 100 & 96 & 98 & 78 \\
\hline
\end{tabular}

a THF $4.0 \mathrm{ml}$.

b $s t$-PMMA macromonomer: $\overline{\mathrm{DP}}=32.1 ; m m: m r: r r=1: 10: 89 ; f=0.89$.

c Initiator.

${ }^{d}$ Determined by ${ }^{1} \mathrm{H}$ NMR spectroscopy.

e Total, total yield of polymerization mixture; graft polymer, yield of fractionated graft polymer.

$167.32 \mathrm{ppm}$. These values are close to the corresponding ones of MMA and EMA observed under the same conditions $\left(\mathrm{CDCl}_{3}, 35^{\circ} \mathrm{C}\right)$, MMA; $\mathrm{CH}_{2}=125.29,=\mathrm{C} 136.28, \mathrm{C}=\mathrm{O}$ 167.88 ppm, EMA; $\mathrm{CH}_{2}=124.99,=\mathrm{C} 136.60$, $\mathrm{C}=\mathrm{O} 167.44 \mathrm{ppm}$.

\section{Copolymerization of st-PMMA Macromono- mer}

Anionic copolymerization of st-PMMA macromonomer with MMA or EMA was carried out in THF with DPHLi at $-78^{\circ} \mathrm{C}$. The results are shown in Table IV. The reaction products were recovered by precipitation into hexane and thus might contain unreacted macromonomer. However, the ${ }^{1} \mathrm{H}$ NMR spectra of all the products did not show any peaks due to vinylidene protons of the macromonomer. The results mean that the conversions of the macromonomer are $100 \%$ in all the cases. The GPC chromatogram for the product from the copolymerization with EMA is shown in Figure $2 \mathrm{a}$ as an example. The chromatogram indicated the presence of low molecular weight fraction, which should not be the starting macromonomer itself but PMMA without methacryloyl function contained in the starting material and the product from the macromonomer reacted but failed to

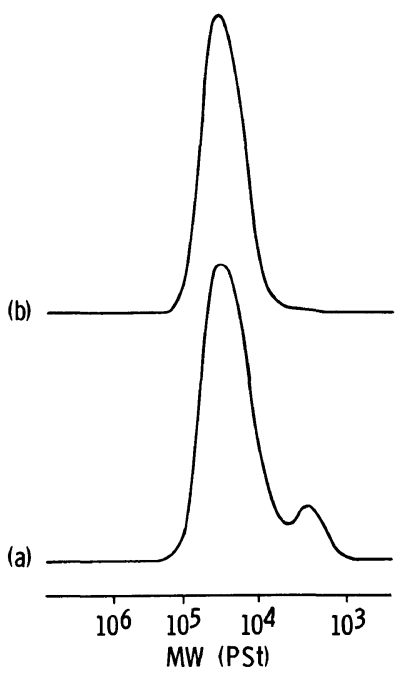

Figure 2. GPC chromatograms of the reaction mixture of the copolymerization of st-PMMA macromonomer with EMA by DPHLi in THF at $-78^{\circ} \mathrm{C}$ (a) and the graft polymer fractionated therefrom (b).

propagate further. The graft polymer was fractionated from the product by repeated precipitation in toluene-hexane mixtures. The GPC curve of the graft polymer shown in Figure $2 b$ corresponds to that of the higher molecular weight fraction of the product mixture (Figure 2a).

The characteristics of the graft polymers are shown in Table V. The triad tacticities** of

** The main-chain tacticities of the graft polymers are cotacticities in a strict sense. However, the term, tacticity, is used in this paper for the simplicity. 
Table V. Characteristics of graft polymer of $s t$-PMMA macromonomer (Mac) and methacrylate monomer (RMA) prepared with DPHLi in $\mathrm{THF}$ at $-78^{\circ} \mathrm{C}$

\begin{tabular}{|c|c|c|c|c|c|c|c|c|}
\hline \multirow{2}{*}{ RMA } & \multirow{2}{*}{$\mathrm{RMA} / \mathrm{Mac}^{\mathrm{a}}$} & \multicolumn{2}{|c|}{$\bar{M}_{n}$} & \multirow{2}{*}{$\bar{M}_{w} / \bar{M}_{n}^{\mathrm{b}}$} & \multicolumn{3}{|c|}{ Tacticity $/ \%$} & \multirow{2}{*}{$\begin{array}{c}\text { Number } \\
\text { of } \\
\text { branch }^{\mathrm{d}}\end{array}$} \\
\hline & & GPC & NMR & & $m m$ & $m r$ & $r r$ & \\
\hline MMA & 14.7 & 26500 & 32500 & 1.35 & 0 & 22 & 78 & 6.62 \\
\hline EMA & 2.8 & 21300 & 21900 & 1.34 & 0 & 14 & 86 & 5.82 \\
\hline EMA & 8.9 & 27300 & 35100 & 1.39 & 0 & 12 & 88 & 7.89 \\
\hline
\end{tabular}

a Monomeric unit ratio of RMA and st-PMMA macromonomer in the graft polymer.

b Determined by GPC based on the calibration against linear polystyrene samples.

c Tacticity of the main chain determined by ${ }^{13} \mathrm{C}$ NMR spectroscopy.

${ }^{d}$ Determined by ${ }^{1} \mathrm{H}$ NMR spectroscopy.

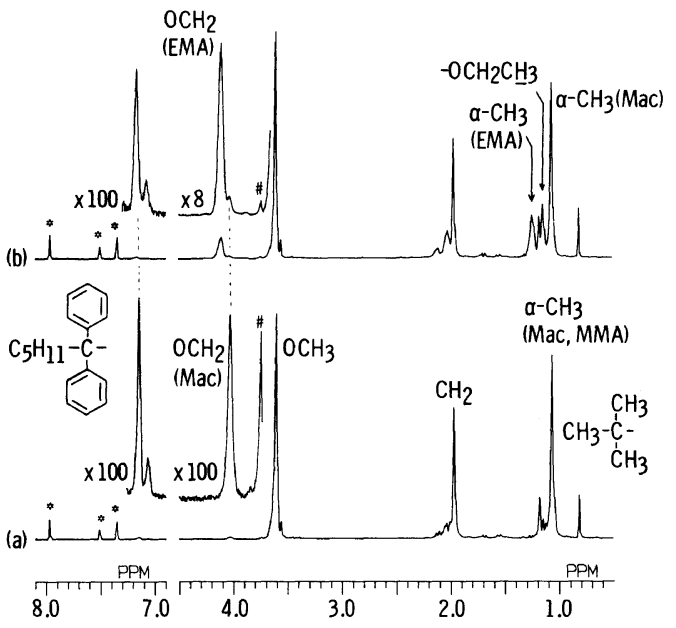

Figure 3. $500 \mathrm{MHz}{ }^{1} \mathrm{H} \quad \mathrm{NMR}$ spectra of the graft polymers of st-PMMA macromonomer with MMA (a) and with EMA (b) prepared by DPHLi in THF at $-78^{\circ} \mathrm{C}$ measured in nitrobenzene- $d_{5}$ at $110^{\circ} \mathrm{C}$.

* Signals due to the remaining protons in nitrobenzene- $d_{5}$.

\# ${ }^{13} \mathrm{C}$ satellite signal of $\mathrm{OCH}_{3}$ signal.

the main chain were determined by ${ }^{13} \mathrm{C}$ NMR spectroscopy as described later. The composition of the graft polymer with EMA main chain could be determined from $1 \mathrm{H}$ NMR spectrum (Figure $3 \mathrm{~b}$ ) from the comparison of peak intensities of $\mathrm{OCH}_{2}$ (EMA) at $4.12 \mathrm{ppm}$ and $\mathrm{OCH}_{3}$ (macromonomer) at $3.61 \mathrm{ppm}$ by assuming that the $\bar{M}_{n}$ of the PMMA branches in the graft polymer was the same as that of the starting macromonomer. It should be noted that $\mathrm{OCH}_{2}$ protons of the macro- monomer unit resonated at $4.04 \mathrm{ppm}$ as observed in the ${ }^{1} \mathrm{H}$ NMR spectrum of the graft polymer with MMA main chain (Figure 3a) and thus partly overlapped with the $\mathrm{OCH}_{2}$ protons of EMA unit. Therefore, the contribution of the methylene proton signals due to the macromonomer unit in the signals around $4.04 \mathrm{ppm}$ was subtracted by taking the $\overline{D P}$ of the macromonomer into account.

In the case of the graft polymer prepared from the macromonomer and MMA, a similar analysis for the composition is difficult because MMA units in the main chain and those in the side chains are indistinguishable by ${ }^{1} \mathrm{H}$ NMR spectroscopy; $\mathrm{OCH}_{3}$ signal observed is the superpose of the signals from both MMA units. However, as mentioned above, $\mathrm{OCH}_{2}$ signal due to the macromonomer units could be observed separately from $\mathrm{OCH}_{3}$ signal of MMA units, and the contribution of the side-chain MMA unit could be subtracted by assuming the $\overline{D P}$ of the st-PMMA branches to be equal to that of the starting macromonomer.

DPHLi is an efficient initiator for the living polymerization of methacrylate monomers in THF at low temperature. ${ }^{15-17}$ Thus the polymer formed with this initiator should contain one 1,1-diphenylhexyl group at its initiating chain end: 


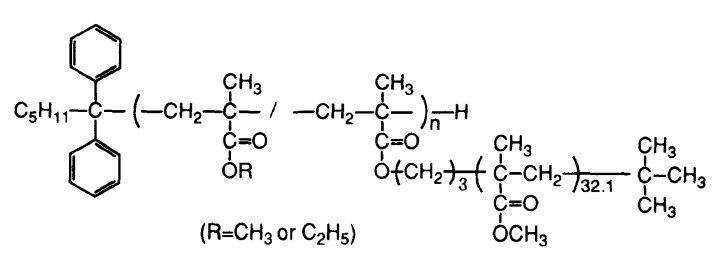

Thus the number of PMMA branches could be determined directly from the relative peak intensities of the phenyl protons (6.95$7.25 \mathrm{ppm}$ ) and $t-\mathrm{C}_{4} \mathrm{H}_{9}$ protons. The $\bar{M}_{n}$ of the graft polymer could be determined from the number of branch $(N)$ and the composition ( $C=[\mathrm{RMA}] /[$ macromonomer $]$ );

$$
\begin{aligned}
\bar{M}_{n}= & N \times\left(\bar{M}_{n} \text { of macromonomer }\right) \\
+ & C \times N \times(\text { molecular weight of } \\
& \text { comonomer unit }) \\
+ & (\text { molecular weight of initiator } \\
& \text { fragment })+1
\end{aligned}
$$

The values shown in Table $\mathrm{V}$ are fairly consistent with $\bar{M}_{n}$ estimated by GPC, confirming the NMR analysis. The slightly smaller $\bar{M}_{n}$ values obtained from GPC analyses may be due to the smaller hydrodynamic volume of graft polymer as compared with the corresponding linear polymer.

Main-chain methylene proton regions in the
${ }^{1} \mathrm{H}$ NMR spectra of the graft polymers did not show meso methylene signals due to MMA or EMA units in the main chain, suggesting that the main-chain tacticity is predominantly syndiotactic. The quantitative data were obtained by ${ }^{13} \mathrm{C}$ NMR spectroscopy as described later.

Anionic copolymerization of the macromonomer with MMA or EMA was carried out in toluene at $-78^{\circ} \mathrm{C}$ using $t-\mathrm{C}_{4} \mathrm{H}_{9} \mathrm{MgBr}$ as an initiator (Table VI). Polymerization of MMA alone under the same conditions proceeds in a living manner to give highly isotactic PMMA. ${ }^{14}$ The conversions of the macromonomer were lower than those in the copolymerizations with DPHLi (Table IV), indicating that the rate of polymerization with respect to the macromonomer was smaller for the copolymerization with $t-\mathrm{C}_{4} \mathrm{H}_{9} \mathrm{MgBr}$ in toluene than for that with DPHLi in THF, as observed for the polymerizations of low molecular weight methacrylates such as MMA and EMA. The conversions of EMA were close to $100 \%$ in all the experiments, and it is not possible to discuss the reactivities of EMA in these copolymerizations. Molecular weight distributions (MWD's) of the graft polymers were bimodal and broader than those for the

\begin{tabular}{|c|c|c|c|c|c|c|c|c|}
\hline \multirow{2}{*}{$\frac{\mathrm{Mac}^{\mathrm{b}}}{\mathrm{mmol}}$} & \multirow{2}{*}{$\frac{\text { Comonomer }}{\text { RMA (mmol) }}$} & \multirow{2}{*}{$\frac{\text { RMA }}{\mathrm{Mac}^{\mathrm{b}}}$} & \multirow{2}{*}{$\frac{\text { Init. }^{\mathrm{c}}}{\mathrm{mmol}}$} & \multirow{2}{*}{ Time } & \multicolumn{2}{|c|}{ Conversion $^{\mathrm{d}} / \%$} & \multicolumn{2}{|c|}{ Yielde $/ \%$} \\
\hline & & & & & $\mathrm{Mac}^{\mathrm{b}}$ & RMA & Total & Graft polymer \\
\hline 0.13 & MMA (1.40) & 10.8 & 0.060 & 15.9 & 65 & - & 100 & $36^{\mathrm{f}}, 26^{\mathrm{g}}$ \\
\hline 0.13 & EMA $(0.70)$ & 5.8 & 0.063 & 11.8 & 78 & 91 & 95 & 49 \\
\hline 0.13 & EMA (1.32) & 10.0 & 0.058 & 15.9 & 83 & 98 & 100 & 67 \\
\hline
\end{tabular}
graft polymers prepared with DPHLi. The GPC curve of the reaction product from the

Table VI. Copolymerization of st-PMMA macromonomer (Mac) and methacrylate monomer (RMA) with $t-\mathrm{C}_{4} \mathrm{H}_{9} \mathrm{MgBr}$ in toluene at $-78^{\circ} \mathrm{C}^{\mathrm{a}}$

a Toluene $4.0 \mathrm{ml}$.

b $s t$-PMMA macromonomer: $\overline{\mathrm{DP}}=32.1 ; m m: m r: r r=1: 10: 89 ; f=0.89$.

c Initiator.

d Determined by ${ }^{1} \mathrm{H}$ NMR spectroscopy.

e Total, total yield of polymerization mixture; graft polymer, yield of fractionated graft polymer.

f The higher molecular weight fraction of the graft polymer (see Figure 4c).

g The lower molecular weight fraction of the graft polymer (see Figure 4b). 
copolymerization of the macromonomer with MMA is shown in Figure 4a as an example.

The reaction product of the macromonomer and MMA was soluble in chloroform but partly insoluble in toluene, in which stereocomplex formation between $i t$ - and st-PMMAs takes place. ${ }^{21}$ The graft polymer was separated

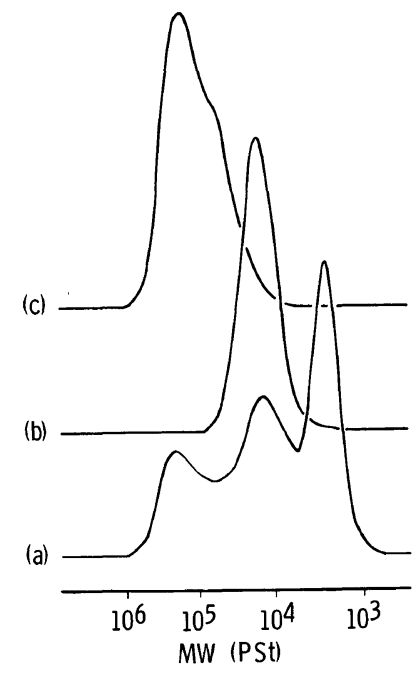

Figure 4. GPC chromatograms of the reaction mixture of the copolymerization of st-PMMA macromonomer with MMA by $t-\mathrm{C}_{4} \mathrm{H}_{9} \mathrm{MgBr}$ in toluene at $-78^{\circ} \mathrm{C}$ (a) and the lower (b) and the higher molecular weight fractions (c) of the graft polymer obtained therefrom. from the product by repeated precipitation in chloroform-hexane mixtures, and was further fractionated into higher and lower molecular weight fractions as shown in Figures $4 b$ and $4 c$. The compositions of these graft polymers were determined from their ${ }^{1} \mathrm{H}$ NMR spectra in a similar manner to those of the graft polymers formed with DPHLi. The compositions of the higher and lower molecular weight fractions were fairly close to each other as shown in Table VII.

The ${ }^{1} \mathrm{H}$ NMR spectrum of the fractionated graft polymer is shown in Figure 5a. The main-chain methylene proton region showed meso methylene signals along with racemo ones due to the macromonomer units, indicating that the tacticity of the main-chain MMA sequence was isotactic and the quantitative data for the tacticity were determined by ${ }^{13} \mathrm{C}$ NMR spectroscopy to be highly isotactic as described later. The results suggest that there exist at least two types of active species which are different in reactivity but both highly isotactic-specific. A similar phenomenon has been observed for the copolymerization of MMA and EMA with $t-\mathrm{C}_{4} \mathrm{H}_{9} \mathrm{MgBr}$ in toluene at low temperature. ${ }^{22}$

Since the $t-\mathrm{C}_{4} \mathrm{H}_{9}$ groups at the initiating

Table VII. Characteristics of graft polymer of st-PMMA macromonomer (Mac) and methacrylate monomer (RMA) prepared with $t-\mathrm{C}_{4} \mathrm{H}_{9} \mathrm{MgBr}$ in toluene

\begin{tabular}{|c|c|c|c|c|c|c|c|c|}
\hline \multirow{2}{*}{ RMA } & \multirow{2}{*}{$\mathrm{RMA} / \mathrm{Mac}^{\mathrm{a}}$} & \multicolumn{2}{|c|}{$\bar{M}_{n}$} & \multirow{2}{*}{$\bar{M}_{w} / \bar{M}_{n}^{\mathrm{b}}$} & \multicolumn{3}{|c|}{ Tacticity $/ \%$} & \multirow{2}{*}{$\begin{array}{c}\text { Number } \\
\text { of } \\
\text { branch }\end{array}$} \\
\hline & & GPC & NMR & & $\mathrm{mm}$ & $m r$ & $r r$ & \\
\hline $\mathrm{MMA}^{\mathrm{d}}$ & 22.2 & $77300^{f}$ & 101800 & 2.63 & 99 & 1 & 0 & $18.1^{\mathrm{h}}$ \\
\hline $\mathrm{MMA}^{\mathrm{e}}$ & 23.9 & $15300^{f}$ & 14200 & 1.27 & 96 & 4 & 0 & $2.45^{\mathrm{h}}$ \\
\hline EMA & 4.5 & $22000^{\mathrm{g}}$ & - & 2.10 & 84 & 11 & 5 & $5.74^{\mathrm{i}}$ \\
\hline EMA & 9.1 & $41400^{\mathrm{g}}$ & - & 3.38 & 85 & 7 & 8 & $9.51^{\mathrm{i}}$ \\
\hline
\end{tabular}

a Monomeric unit ratio of RMA and st-PMMA macromonomer in the graft polymer.

b Determined by GPC based on the calibration against linear polystyrene samples.

c Tacticity of the main chain determined by ${ }^{13} \mathrm{C}$ NMR spectroscopy.

d The higher molecular weight fraction of the graft polymer (see Figure 4c).

e The lower molecular weight fraction of the graft polymer (see Figure $4 \mathrm{~b}$ ).

f Measured in chloroform.

$\mathrm{g}$ Measured in THF.

h Determined by ${ }^{1} \mathrm{H}$ NMR spectroscopy.

i Estimated from $\bar{M}_{n}$ determined by GPC and composition. 


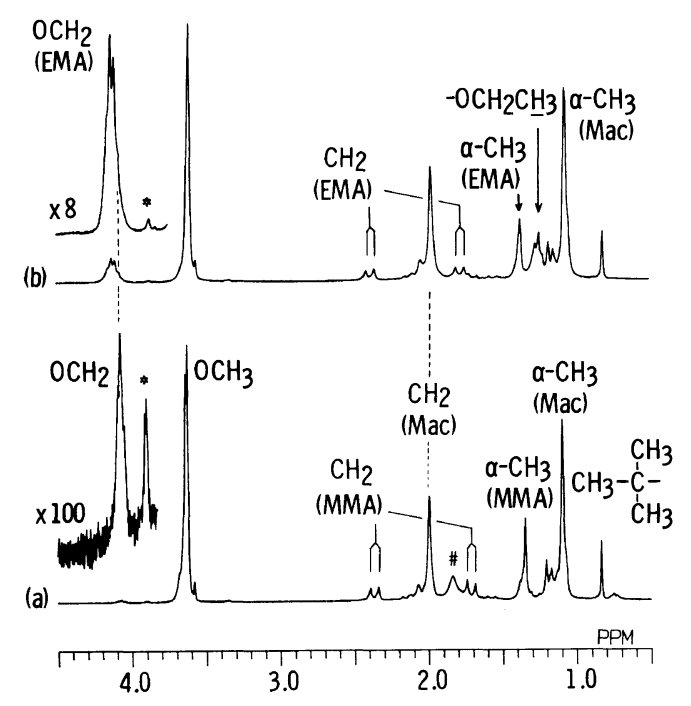

Figure 5. $270 \mathrm{MHz}{ }^{1} \mathrm{H}$ NMR spectra of the graft polymers of st-PMMA macromonomer with MMA (a) and with EMA (b) prepared by $t-\mathrm{C}_{4} \mathrm{H}_{9} \mathrm{MgBr}$ in toluene at $-78^{\circ} \mathrm{C}$ measured in nitrobenzene- $d_{5}$ at $110^{\circ} \mathrm{C}$. (a) The lower molecular weight fraction of the graft polymer (see Figure 4b).

${ }^{*}{ }^{13} \mathrm{C}$ satellite signal of $\mathrm{OCH}_{3}$ signal.

\# Signal due to incidentally introduced water.

chain end and the terminal of the branches did not show different ${ }^{1} \mathrm{H}$ NMR chemical shift, direct determination of number of branch in the graft polymer from end group analysis by NMR was difficult. However, the peak intensity for the $t-\mathrm{C}_{4} \mathrm{H}_{9}$ at the initiating chain end could be determined by subtracting the contribution from the $t-\mathrm{C}_{4} \mathrm{H}_{9}$ group at the branch ends, which was estimated from the peak intensity of $\mathrm{OCH}_{2}$ protons of the macromonomer unit.

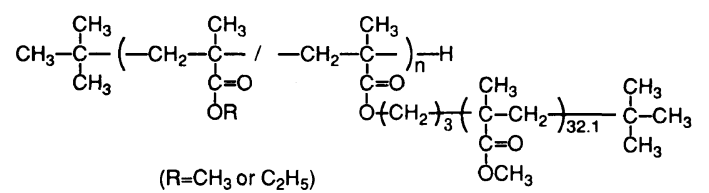

The obtained $\bar{M}_{n}$ values are shown in Table VII, which agree well with those estimated by GPC.

The graft polymer obtained from the copolymerization of st-PMMA macromonomer with EMA by $t-\mathrm{C}_{4} \mathrm{H}_{9} \mathrm{MgBr}$ was also separated from the reaction product by repeated precipitation from toluene-hexane mixtures. MWD's of the graft polymers were bimodal and much broader than those for the graft polymers prepared with DPHLi. The compositions were determined in the same way as the case of graft polymers prepared with DPHLi. For the determination of the number of branch, the ratio of $t-\mathrm{C}_{4} \mathrm{H}_{9}$ group at the initiation chain end to that of the macromonomer unit (branch end) should be estimated. However, since the $\mathrm{OCH}_{2}$ signals due to the macromonomer unit overlapped with those of EMA unit as shown in Figure 5b, the peak intensity of the latter $t-\mathrm{C}_{4} \mathrm{H}_{9}$ group could not be determined from the intensity of the $\mathrm{OCH}_{2}$ protons and should be estimated from the intensity of $\mathrm{OCH}_{3}$ and the $\overline{D P}$ of the macromonomer. Even a small error in the estimation of the peak intensity of the branch-end $t-\mathrm{C}_{4} \mathrm{H}_{9}$ group results in a large error in the determination of the ratio of the two $t-\mathrm{C}_{4} \mathrm{H}_{9}$ groups. As the first approximation, therefore, the number of branch of the graft polymer was estimated based on the $\bar{M}_{n}$ determined by GPC and the composition (Table VII).

\section{Stereoregularity of the Main Chain}

From the methylene proton signals in the ${ }^{1} \mathrm{H}$ NMR spectra, main-chain stereoregularity of the graft polymers prepared with DPHLi and $t-\mathrm{C}_{4} \mathrm{H}_{9} \mathrm{MgBr}$ were found to be syndiotactic and isotactic, respectively. For the quantitative determination of the tacticity, ${ }^{13} \mathrm{C}$ NMR spectra of the graft polymers were measured in chloroform- $d$ at $55^{\circ} \mathrm{C}$.

Figure 6 illustrates the carbonyl carbon spectra of the graft polymers prepared from st-PMMA macromonomer and MMA or EMA with DPHLi, along with those of the macromonomer and poly(EMA) prepared with DPHLi in THF at $-78^{\circ} \mathrm{C}$. Commonly observed signals in these spectra are mostly due to MMA units in the macromonomer chains. The spectrum of the graft polymer 


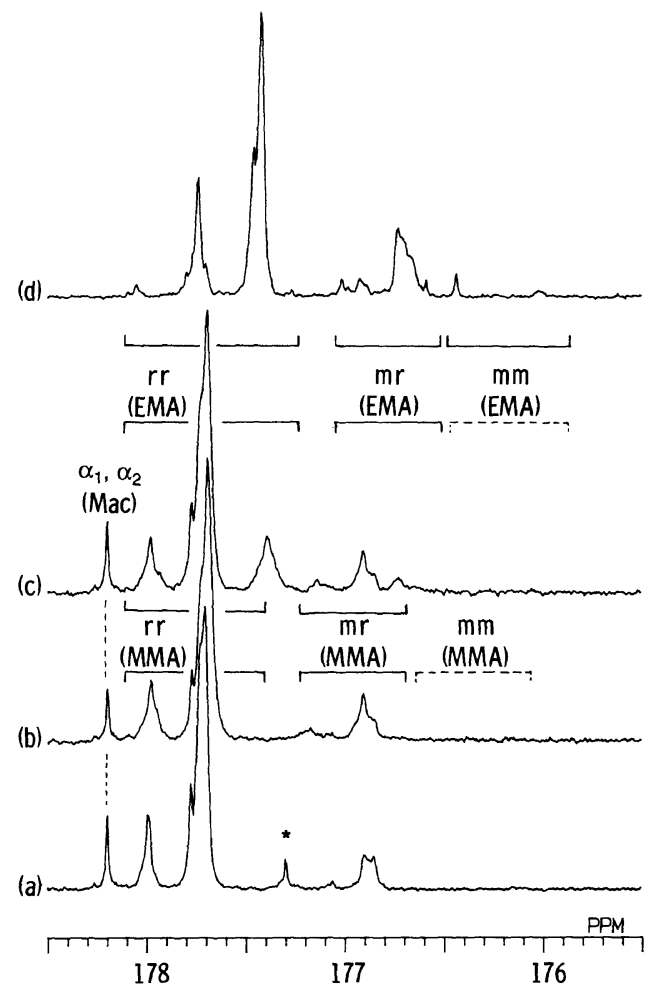

Figure 6. $67.8 \mathrm{MHz}{ }^{13} \mathrm{C}$ NMR spectra of carbonyl carbons of st-PMMA macromonomer (a), the graft polymers with MMA (b) and with EMA (c) prepared with DPHLi in THF at $-78^{\circ} \mathrm{C}$, and poly(EMA) (d) prepared under the same conditions. The spectra were measured in chloroform- $d$ at $55^{\circ} \mathrm{C}$.

* The signal was not observed in the spectrum of st-PMMA ${ }^{23}$ and is probably due to the $\omega$ end unit, - $-\left(\mathrm{CH}_{2}\right)_{3}-\stackrel{\mathrm{C}_{\text {I }}^{\mathrm{C}}-\mathrm{CH}_{3}-}{\mathrm{C}}$, of the macromonomer.

with EMA main chain (Figure 6c) showed new peaks ascribable to heterotactic (176.7 ppm) and syndiotactic $(177.4 \mathrm{ppm})$ sequences of EMA units. Comparing the spectrum of the graft polymer (Figure 6c) with that of poly(EMA) (Figure 6d), the signals due to EMAcentered syndiotactic and heterotactic sequences are expected to be observed in the shift ranges shown in Figure 6c. The signals due to isotactic sequence were not observed in the spectrum because of the lower content of isotactic sequence, but are expected to be

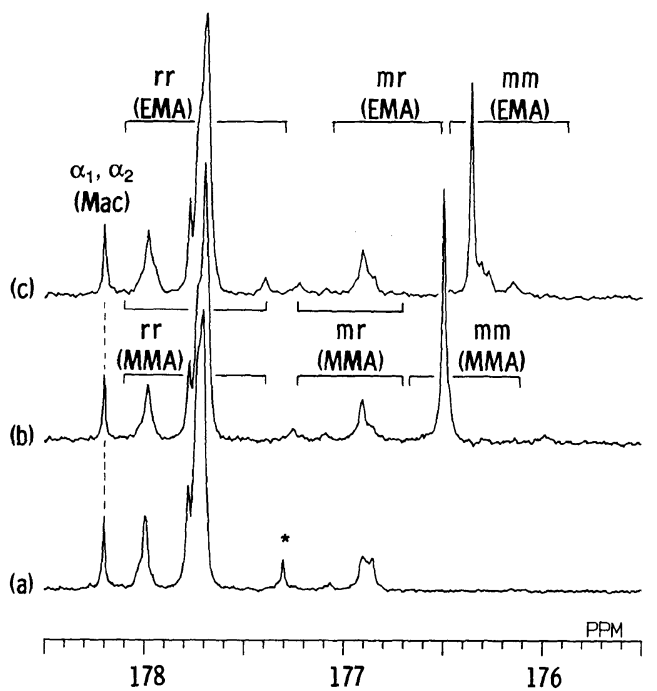

Figure 7. $67.8 \mathrm{MHz}{ }^{13} \mathrm{C}$ NMR spectra of carbonyl carbons of st-PMMA macromonomer (a), and the graft polymers with MMA (b) and with EMA (c) prepared with $t-\mathrm{C}_{4} \mathrm{H}_{9} \mathrm{MgBr}$ in toluene at $-78^{\circ} \mathrm{C}$ measured in chloroform- $d$ at $55^{\circ} \mathrm{C}$. (b) The lower molecular weight fraction (see Figure $4 \mathrm{~b}$ ).

* The signal was not observed in the spectrum of $s t$-PMMA ${ }^{23}$ and is probably due to the $\omega$ end unit, $\mathrm{CH}_{3}$

$-\mathrm{O}-\left(\mathrm{CH}_{2}\right)_{3}-\underset{\mathrm{C}}{\mathrm{C}-\mathrm{CH}_{2}-}$, of the macromonomer.

observed at $175.9-176.5 \mathrm{ppm}$ (see Figure 7c). The signals due to the carbonyl carbons of the methacrylate units derived from the methacryloyl function at the end of the macromonomer are also expected to exhibit similar tactic splitting to those of MMA and EMA units, although they were not distinguishable in the spectrum. Anyway, the signals of carbonyl carbons consisted of those from three types of monomer units, that is, MMA units in the side chains, EMA units and the methacryloyl units of the macromonomer in the main chian. Macromonomer units in the graft polymer are mostly flanked by EMA units on both sides. Since the chemical shift difference in tactic triads is usually larger than that in triad monomer sequences, ${ }^{18}$ it is assumed that carbonyl carbon signals due to the main-chain methacrylate units of the 
macromonomer are observed in the same chemical shift ranges as those of MMA and EMA units. In the determination of the mainchain tacticity, the chemical shift ranges for $m m, m r$, and $r r$ triads for all the three types of monomer units are assumed to be $175.85-176.50 \mathrm{ppm}, 176.50-177.20 \mathrm{ppm}$, and $177.20-178.10 \mathrm{ppm}$, respectively (Figure 6c). The chemical shift ranges for $m r$ triad $(m r(\mathrm{EMA})+m r(\mathrm{MMA}))$ partly overlaps with that for $m m$ triad of MMA units (mm(MMA)) (Figure $7 b$ ). Since the signal due to $\mathrm{mm}$ triad of MMA units was not observed in the spectrum of the macromonomer (Figure 6a), the estimation of signal intensity of $m r$ triad was not interfered by the overlapping. An average tacticity of the main chain was determined by subtraction of the signals due to MMA units in the macromonomer chains as follows. The sharp resonance at $178.2 \mathrm{ppm}$ observed in the spectrum of the macromonomer (Figure 6a) can be assigned to the carbonyl carbons in the first and second MMA units at the initiating chain end ( $\alpha_{1}$ and $\alpha_{2}$ units). ${ }^{23}$ The same signal observed in the spectra of the graft polymers was used as an intensity standard for the estimation of the contributions of the macromonomer unit signals. The quantitative condition was fulfilled, since the $\overline{D P}$ (32.2) of the macromonomer estimated from signal intensities of the $\alpha_{1}$ and $\alpha_{2}$ carbonyl carbons relative to those of all the carbonyl carbons agreed well with that determined from the ${ }^{1} \mathrm{H}$ NMR spectrum (32.1). The possibility that the signal due to EMA units overlaps with the $\alpha_{1}$ and $\alpha_{2}$ signal was ruled out by the fact that no peak was observed at $178.2 \mathrm{ppm}$ in the spectrum of carbonyl carbons of poly(EMA) prepared with DPHLi in THF (Figure 6d). Thus, the signal at $178.2 \mathrm{ppm}$ was assumed to be derived from only the $\alpha_{1}$ and $\alpha_{2}$ carbonyl carbons of the macromonomer chains. The same procedure was made in the estimation for the mainchain tacticities of the other graft polymers described later. Tacticities thus determined are shown in Table V.

In the spectrum of the graft polymer with main-chain MMA units, signals from the main-chain MMA units should overlap with those from MMA units of the macromonomer chains. The main-chain tacticity was determined by the same method as mentioned above, based on the assumption that the chemical shift ranges for $m m, m r$, and $r r$ triads are $176.10-176.65 \mathrm{ppm}, 176.65-177.25 \mathrm{ppm}$, and $177.40-178.10 \mathrm{ppm}$, respectively. Tacticity thus determined is shown in Table V.

The main-chain tacticities of all the graft polymers were predominantly syndiotactic. Tacticities of PMMA and poly(EMA) formed under the same conditions were as follows; PMMA, $m m: m r: r r=2: 19: 79$, and poly(EMA), $m m: m r: r r=1: 23: 76$. The syndiotacticities of the graft polymers with EMA main-chain units were higher than that of poly(EMA). The higher syndiotacticities for the graft polymers might be caused by the steric effect of the macromonomer chain. However, the considerable overlap between the signals from main-chain units should make it difficult to discuss the differences in tacticity due to the low precision of the values of tacticities.

In the ${ }^{13} \mathrm{C}$ NMR spectra of the graft polymers formed with $t-\mathrm{C}_{4} \mathrm{H}_{9} \mathrm{MgBr}$ in toluene (Figure 7), the new peaks ascribable to MMA or EMA units in isotactic main chain were observed (Figures $7 \mathrm{~b}$ and $7 \mathrm{c}$ ). The tacticities were estimated by the same method as described previously and found to be highly isotactic as shown in Table VII. In the determination of the main-chain tacticities of the graft polymers, the chemical shift ranges for $m m, m r$, and $r r$ triads for all the monomer units are assumed to be the same ranges as those for the graft polymers formed with DPHLi (the graft polymer with EMA main chain, $m m$ : $175.85-176.50 \mathrm{ppm}, m r: 176.50$ $177.20 \mathrm{ppm}, r r: 177.20-178.10 \mathrm{ppm}$; the graft polymer with MMA main chain, $m m: 176.10$ $176.65 \mathrm{ppm}, m r: 176.65-177.25 \mathrm{ppm}, r r$ : 
Table VIII. Intrinsic viscosity and Huggins' coefficient $\left(k_{\mathrm{H}}\right)$ of the graft polymers of MMA and PMMA measured in chloroform or acetone at $35^{\circ} \mathrm{C}$

\begin{tabular}{|c|c|c|c|c|c|c|}
\hline \multirow{2}{*}{ Polymer } & \multirow{2}{*}{$\begin{array}{c}\text { Number } \\
\text { of } \\
\text { branch }\end{array}$} & \multirow{2}{*}{$\begin{array}{l}\overline{\mathrm{DP}} \text { of } \\
\text { main } \\
\text { chain }\end{array}$} & \multicolumn{2}{|c|}{ Chloroform } & \multicolumn{2}{|c|}{ Acetone } \\
\hline & & & {$[\eta] / \mathrm{dl} \cdot \mathrm{g}^{-1}$} & $k_{\mathrm{H}}$ & {$[\eta] / \mathrm{dl} \cdot \mathrm{g}^{-1}$} & $k_{\mathrm{H}}$ \\
\hline$s t$-Graft polymer ${ }^{\mathrm{a}}$ & 6.62 & 103.9 & 0.139 & 0.86 & 0.086 & 1.57 \\
\hline it-Graft polymer ${ }^{\mathrm{b}}$ & 2.45 & 61.0 & 0.111 & 1.23 & 0.072 & 4.99 \\
\hline$s t$-PMMA ${ }^{\mathrm{c}}$ & & 226.1 & 0.220 & 0.88 & 0.118 & 1.35 \\
\hline \multirow{2}{*}{\multicolumn{2}{|c|}{$\begin{array}{l}i t-\mathrm{PMMA}^{\mathrm{d}}+s t-\mathrm{Macromonomer}^{\mathrm{e}}(42: 58) \\
s t-\mathrm{Macromonomer}^{\mathrm{e}}\end{array}$}} & & 0.070 & 1.23 & 0.057 & 1.82 \\
\hline & & 32.1 & 0.055 & 1.25 & 0.040 & 1.48 \\
\hline
\end{tabular}

a The graft polymer prepared with DPHLi in THF (see Table V).

b The lower molecular weight fraction of the graft polymer prepared with $t-\mathrm{C}_{4} \mathrm{H}_{9} \mathrm{MgBr}$ in toluene (see Table VII and Figure $4 b)$.

c $s t$-PMMA $\left(\bar{M}_{n}=22700 ; \bar{M}_{w} / \bar{M}_{n}=1.26 ; m m: m r: r r=0: 11: 89\right)$.

d $i t$-PMMA $\left(\bar{M}_{n}=5370 ; \bar{M}_{w} / \bar{M}_{n}=1.10 ; m m: m r: r r=97: 2: 1\right)$.

e $s t$-PMMA macromonomer $\left(\bar{M}_{n}=3400 ; \bar{M}_{w} / \bar{M}_{n}=1.07 ; m m: m r: r r=1: 10: 89\right)$.

\section{$177.40-178.10 \mathrm{ppm})$.}

The main-chain tacticities of the graft polymer with main-chain MMA units were close to those of PMMA obtained under the same conditions $(m m: m r: r r=96: 4: 0) .{ }^{14}$ The tacticities for the graft polymer with mainchain EMA units were a little different from those of poly(EMA) formed under the same conditions $(m m: m r: r r=97: 3: 0){ }^{22}$ This is partly due to the higher content of macromonomer unit in the chain, which may decrease isotacticity of the EMA sequence. Thus the anionic copolymerization of stPMMA macromonomer and methacrylate monomers could give the graft polymers with controlled main-chain stereoregularities with highly stereoregular side chains.

It should be noted that the graft polymer obtained from the macromonomer and MMA with $t-\mathrm{C}_{4} \mathrm{H}_{9} \mathrm{MgBr}$ comprises of the main chain and the side chains with opposite stereoregularities, namely, isotactic main chain with syndiotactic side chains. As described previously, the higher molecular weight fraction of the graft polymer was insoluble in toluene at room temperature, suggesting that the polymer formed the stereocomplex. The solid polymer showed endothermic peak in DSC thermogram due to the melting of the stereo- complex $\left(141.5^{\circ} \mathrm{C}\right)$, melting point of which was lower than that of stereocomplex formed between linear it- and st-PMMAs with similar $\bar{M}_{n}$ 's. The lower molecular weight fraction, however, was soluble in toluene and in acetone, which is also known as a complex forming solvent, probably due to short isotactic sequence in the main chain.

\section{Characteristics of Stereoregular Graft Polymers}

Some of the solution properties of the stereoregular graft polymers of MMA were examined. Table VIII summarizes the intrinsic viscosities [ $\eta]$ 's and the Huggins' coefficients $k_{\mathrm{H}}$ 's of the graft polymers in chloroform and in acetone. Graft polymer with syndiotactic main chain (st-graft polymer) showed lower viscosity than linear st-PMMA of a similar $\bar{M}_{n}$ as commonly observed for branched polymers. ${ }^{24}$ The $k_{\mathrm{H}}$ 's for these $s t$-polymers did not differ significantly. We reported that homopolymers of it- and st-PMMA macromonomers exhibited larger $k_{\mathrm{H}}$ values than the corresponding linear PMMAs. ${ }^{8}$ The smaller difference of $k_{\mathrm{H}}$ values in the present case may be due to the smaller branching density than the polymacromonomers.

While the different numbers of branch per chain and the different $\bar{M}_{n}$ 's do not allow 
direct comparison of $[\eta]$ 's between graft polymer with isotactic main chain (it-graft polymer) and the st-graft polymer, $k_{\mathbf{H}}$ values for these graft polymers are apparently different, especially in acetone. The large $k_{\mathrm{H}}$ of the it-graft polymer (4.99), or strong dependence of reduced viscosity on concentration (the range of the concentration; $0.25-1.00 \mathrm{~g} \mathrm{dl}^{-1}$ ), suggests the possibility of association of the polymer in acetone. Absolute peak intensities in the ${ }^{1} \mathrm{H}$ NMR spectrum of the graft polymer in acetone- $d_{6}(1 \mathrm{w} / \mathrm{v} \%)$ at $35^{\circ} \mathrm{C}$ was $61 \%$ of the expected value and thus indicated that $39 \%$ of the polymer did not show the signals due to association, that is, stereocomplex formation. Viscosity and ${ }^{1} \mathrm{H}$ NMR measurements of a mixture of it-PMMA of $\overline{D P}=$ 53.1 and the st-PMMA macromonomer as a reference sample for the it-graft polymer were carried out under the same conditions. The mixture also exhibited large $k_{\mathrm{H}}(1.82)$ and diminished ${ }^{1} \mathrm{H}$ NMR signal intensity in acetone- $d_{6}$ ( $68 \%$ of the theoretical value). The degree of association in acetone at $35^{\circ} \mathrm{C}$ as observed from ${ }^{1} \mathrm{H}$ NMR intensity was not so different between the mixture and the $i t$-graft polymer. However, the $k_{\mathrm{H}}$ value for the latter was almost three times as large as that for the former, though the $k_{\mathrm{H}}$ values exceeded the range usually observed. The it-graft polymer may undergo, at least in part, intramolecular association between isotactic main chain and st-PMMA branch, and thus exist as shrinked particles. This might be one of the reasons for the large $k_{\mathrm{H}}$ value, since spherical particles in solution usually exhibit large $k_{\mathrm{H}}$ values, that is, strong concentration dependence of reduced viscosity $\left(\eta_{\mathrm{sp}} / c\right) .{ }^{24}$ Intermolecular association due to the complex formation should become significant as the concentration increases. The intermolecular association in the it-graft polymer may be weakened by the occurrance of the intramolecular association. Such a weak association is expected to be sensitive to concentration and thus cause further enhancement of concentration dependence of $\eta_{\mathrm{sp}} / c$, i.e., larger $k_{\mathrm{H}}$.

\section{REFERENCES}

1. R. Milkovich and M. T. Chiang, U.S. Patent, 3,786,116 (1974); R. Milkovich, Polym. Prepr., Polym. Chem. Div., Am. Chem. Soc., 21, 40 (1980).

2. P. F. Rempp and E. Franta, Adv. Polym. Sci., 58, 1 (1984).

3. Y. Yamashita, J. Appl. Polym. Sci., Appl. Polym. Symp., 36, 193 (1981).

4. R. Asami and M. Takaki, Makromol. Chem., Rapid Commun., 12, 163 (1985).

5. K. Ito, Kobunshi Kako (Polymer Applications), 35, 262 (1986).

6. K. Hatada, H. Nakanishi, K. Ute, and T. Kitayama, Polym. J., 18, 581 (1986).

7. K. Hatada, T. Shinozaki, K. Ute, and T. Kitayama, Polym. Bull., 19, 231 (1988).

8. K. Hatada, T. Kitayama, K. Ute, E. Masuda, T. Shinozaki, and M. Yamamoto, Polym. Bull., 21, 165 (1989).

9. K. Hatada, T. Kitayama, E. Masuda, and M. Kamachi, Makromol. Chem., Rapid Commun., 11, 101 (1990).

10. E. Masuda, S. Kishiro, T. Kitayama, and K. Hatada, Polym. J., 23, 847 (1991).

11. T. Kitayama, S. Kishiro, and K. Hatada, Polym. Bull., 25, 161 (1991).

12. H. Yuki and K. Hatada, Adv. Polym. Sci., 31, 1 (1979).

13. K. Hatada, T. Kitayama, and K. Ute, Prog. Polym. Sci., 13, 189 (1988).

14. K. Hatada, K. Ute, K. Tanaka, Y. Okamoto, and T. Kitayama, Polym. J., 18, 1037 (1986).

15. B. C. Anderson, G. D. Andrews, P. Arthur, Jr., H. W. Jacobson, L. R. Melby, A. J. Playtis, and W. H. Sharkey, Macromolecules, 14, 1599 (1981).

16. P. Luts, P. Masson, G. Beinert, and P. Rempp, Polym. Bull., 12, 79 (1984).

17. Z-K. Cao, Y. Okamoto, and K. Hatada, Kobunshi Ronbunshu, 43, 857 (1986).

18. T. Kitayama, T. Shinozaki, T. Sakamoto, M. Yamamoto, and K. Hatada, Makromol. Chem., Suppl., 15, 167 (1989).

19. R. De Vos and E. J. Goethals, Polym. Bull., 15, 547 (1986).

20. K. Miura, T. Kitayama, K. Hatada, and T. Nakata, Polym. J., 22, 671 (1990).

21. A. M. Liquori, G. Anzuino, V. M. Corio, M. D'Alagni, P. de Santis, and M. Savino, Nature (London), 206, 358 (1965).

22. T. Kitayama, K. Ute, M. Yamamoto, N. Fujimoto, and K. Hatada, Polym. J., 22, 386 (1990).

23. K. Ute, T. Nishimura, and K. Hatada, Polym. J., 21, 1027 (1989).

24. M. Stickler and N. Sutterlin, "Polymer Handbook," 3rd ed., J. Brandrup and E. H. Immergut, Ed., John Wiley \& Sons, New York, N.Y., 1989, Chapter VII, p 183. 